PREPARED FOR THE U.S. DEPARTMENT OF ENERGY, UNDER CONTRACT DE-AC02-76CH03073

PPPL-3943

PPPL-3943

UC-70

Efficient Generation of Non-inductive, Off-axis, Ohkawa Current Driven by Electron Bernstein Waves in High Beta, Spherical Torus Plasmas

by

G. Taylor, P.C. Efthimion, C.E. Kessel, R.W. Harvey, A.P. Smirnov, N.M. Ershov, M.D. Carter, and C.B. Forrest

April 2004
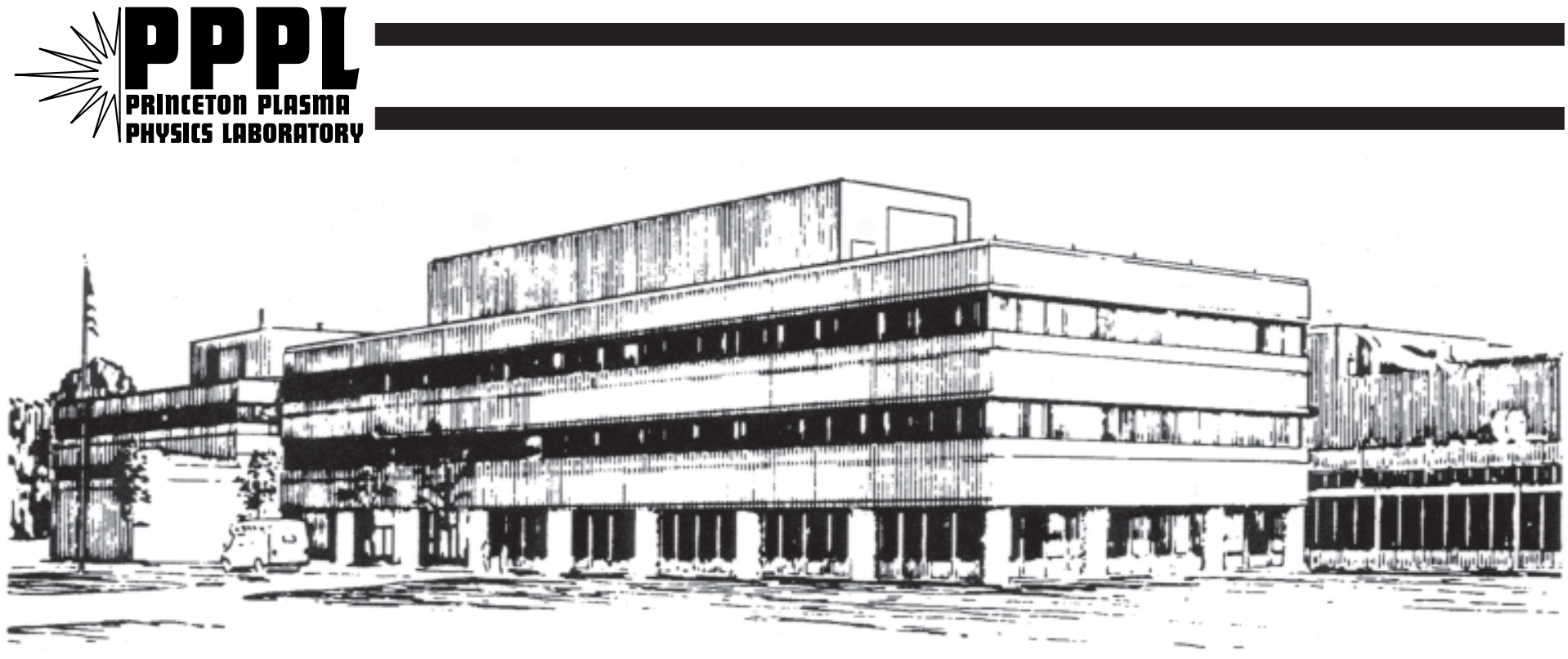

PRINCETON PLASMA PHYSICS LABORATORY PRINCETON UNIVERSITY, PRINCETON, NEW JERSEY 


\section{PPPL Reports Disclaimer}

This report was prepared as an account of work sponsored by an agency of the United States Government. Neither the United States Government nor any agency thereof, nor any of their employees, makes any warranty, express or implied, or assumes any legal liability or responsibility for the accuracy, completeness, or usefulness of any information, apparatus, product, or process disclosed, or represents that its use would not infringe privately owned rights. Reference herein to any specific commercial product, process, or service by trade name, trademark, manufacturer, or otherwise, does not necessarily constitute or imply its endorsement, recommendation, or favoring by the United States Government or any agency thereof. The views and opinions of authors expressed herein do not necessarily state or reflect those of the United States Government or any agency thereof.

\section{Availability}

This report is posted on the U.S. Department of Energy's Princeton Plasma Physics Laboratory Publications and Reports web site in Fiscal Year 2004. The home page for PPPL Reports and Publications is: http://www.pppl.gov/pub_report/

DOE and DOE Contractors can obtain copies of this report from:

U.S. Department of Energy

Office of Scientific and Technical Information

DOE Technical Information Services (DTIS)

P.O. Box 62

Oak Ridge, TN 37831

Telephone: (865) 576-8401

Fax: (865) 576-5728

Email: reports@adonis.osti.gov

This report is available to the general public from:

National Technical Information Service

U.S. Department of Commerce

5285 Port Royal Road

Springfield, VA 22161

Telephone: $1-800-553-6847$ or

(703) $605-6000$

Fax: (703) 321-8547

Internet: http://www.ntis.gov/ordering.htm 


\title{
Efficient generation of non-inductive, off-axis, Ohkawa current, driven by electron Bernstein waves in high $\beta$, spherical torus plasmas
}

\author{
G. Taylor, P.C. Efthimion, C. E. Kessel \\ Princeton Plasma Physics Laboratory, Princeton, NJ 08543, USA \\ R.W. Harvey \\ CompX, Del Mar, CA 920314, USA \\ A.P. Smirnov, N.M. Ershov \\ Moscow State University, Moscow, Russia \\ M.D. Carter \\ Oak Ridge National Laboratory, Oak Ridge, TN 37831, USA \\ C.B. Forest \\ Physics Department, University of Wisconsin, Madison, WI 53706, USA
}

\begin{abstract}
Off-axis rf-driven current can play a critical role in sustaining high $\beta$ spherical torus (ST) plasmas without a central solenoid. Numerical modeling of electron Bernstein wave current drive (EBWCD) for a $\beta \sim 40 \%$ ST plasma predicts efficient, off-axis, Ohkawa EBWCD. Current can be efficiently driven at r/a $>0.5$ where the large trapped electron fraction precludes conventional Fisch-Boozer current drive and provides near-ideal conditions for Ohkawa EBWCD. Also, Ohkawa EBWCD efficiency increases with r/a. Enhancement over Fisch-Boozer current drive is a factor of two at r/a $\sim 0.2$ rising to over an order of magnitude at r/a $\sim 0.5$.
\end{abstract}

PACS\# 52.55.Fa, 52.35.Hr 


\section{INTRODUCTION}

While pressure gradient-driven bootstrap current [1] can provide a large fraction of the plasma current required to non-inductively sustain a magnetically-confined, spherical torus (ST) plasma, an externally driven current may still be required to provide magnetohydrodynamic stability during the plasma current flat top and to assist non-inductive plasma current ramp-up. Efficient, highly localized, off-axis current driven by electron Bernstein waves (EBWs) can provide this non-inductive current and thus may play a critical role in enabling high $\beta$, sustained operation of ST plasmas, without the need for a central solenoid.

Recently, modeling has shown, that to remain ballooning stable, fully non-inductive, $\beta \sim$ 40\% ST plasmas in the National Spherical Torus Experiment (NSTX) [2] require about $10 \%$ of the plasma current to be driven off-axis by an external source [3]. NSTX operates at high electron densities $\left(1-5 \times 10^{19} \mathrm{~m}^{-3}\right)$ relative to its confining magnetic field $(<0.6 \mathrm{~T})$. In this "overdense" regime the electron plasma frequency significantly exceeds the electron cyclotron frequency and, as a consequence, electromagnetic waves at fundamental and low harmonic electron cyclotron frequencies cannot propagate within the plasma. Consequently, conventional electron cyclotron current drive (ECCD) techniques cannot be used in NSTX or other ST plasmas. However, EBWs readily

propagate and are strongly absorbed at the electron cyclotron resonances [4]. These characteristics make EBWs attractive for local electron heating and current drive in a ST. Numerical modeling has shown that localized, EBW current drive (EBWCD) is possible 
in ST plasmas using a perpendicular launch, with the directionality of the EBW-driven current being controlled by launching EBWs above or below the torus midplane [5].

EBW access to the high field side of the magnetic axis is often limited or precluded in high $\beta$ ST plasmas due to the formation of a magnetic field well near the plasma core. Furthermore, electron trapping on the low field side of the magnetic axis in high aspect ratio Tokamaks can significantly reduce the efficiency of conventional, Fisch-Boozer, current drive [6]. In this paper, we show that it is possible to efficiently drive radiallylocalized, off-axis current via the Ohkawa current drive mechanism [7] and thus provide a tool to stabilize magneto-hydrodynamic instabilities that can prevent sustained ST operation at high $\beta$. We have used the GENRAY ray tracing computer code [8] and the CQL3D relativistic, bounce-averaged, Fokker-Planck computer code [9], to model propagation and damping of EBWs and the EBW-driven current density profile for a $\beta$ 40\% NSTX plasma equilibrium.

In section II of this paper we provide a description of the EBWCD modeling, section III presents results from the modeling for a $\beta \sim 40 \%$ NSTX plasma and in section IV we discuss the implications of these results.

\section{DESCRIPTION OF THE EBW MODELING}

The CQL3D code provides a general model of radio-frequency (rf) quasi-linear collisional effects in toroidal plasmas using a bounce-averaged, Fokker-Planck equation to model velocity distributions in two-velocity dimensions and a one-dimensional-noncircular 
radial coordinate. The code is multi-species, and time-dependent. CQL3D [9] is coupled to the GENRAY [8] ray-tracing code to obtain rf damping which is made self-consistent with non-thermal distribution functions by iteration between the Fokker-Planck solution and the rf damping. GENRAY calculates ray trajectories in non-circular and nonaxisymmetric toroidal geometry for several dispersion relations, including the EBW dispersion [5]. Recently, GENRAY has been parallelized to significantly reduce the computation time for multi-ray modeling. Typically, 48 rays were used to model the EBW propagation, with the calculation distributed over 48 central processing units. The Tokamak Simulation Code (TSC) [10] provided the magnetic equilibria and the kinetic profiles used in GENRAY and CQL3D.

\section{EBW CURRENT DRIVE MODELING RESULTS}

TSC results show the possibility for non-inductively sustained, $\beta \sim 40 \%$ NSTX plasmas, predominantly heated by energetic neutral beams. Approximately $90 \%$ of the plasma current is generated by a combination of neutral beam-driven current peaked onaxis and bootstrap-driven current off-axis. The remaining $~ 10 \%$ of the plasma current is driven off-axis, between r/a $~ 0.4$ and r/a $\sim 0.8$, by EBWCD.

EBW-driven current density profiles were calculated for an NSTX target plasma equilibrium with a plasma $\beta=42 \%$, shown in Fig. 1 . This equilibrium has a plasma current of $1 \mathrm{MA}$, a vacuum axial toroidal field of $0.35 \mathrm{~T}$, and a major and minor radius of $0.90 \mathrm{~m}$ and $0.55 \mathrm{~m}$, respectively. Figure 2 shows a plot of characteristic frequencies mapped to the midplane major radius for the equilibrium in Fig.1. The model equilibrium 
is overdense up to the sixth electron cyclotron harmonic. A magnetic field well, resulting from the high plasma $\beta$ is apparent near the magnetic axis. This well effectively constrains accessibility to the high field side of the magnetic axis. Mode conversion from electromagnetic waves to EBWs occurs in the vicinity of the upper hybrid layer $\left(\mathrm{f}_{\mathrm{UH}}\right)$. For launch frequencies above the second harmonic edge electron cyclotron resonance, conversion to EBWs occurs inside the plasma edge at the last closed flux surface.

TSC was benchmarked against an NSTX neutral beam-heated H-mode plasma, shot 109070. The shape of the density profile was fixed to the density profile from shot 109070 and the magnitude was adjusted. Neutral beam characteristics and diffusivities were provided by a TRANSP [11] transport code analysis of shot 109070. Kinetic profiles from TSC used in the modeling are shown in Fig. 3. The electron temperature profile is fairly peaked with a central value of $2 \mathrm{keV}$ (Fig. 3(a)) and the electron density profile is broad, with a central density of $3 \times 10^{19} \mathrm{~m}^{-3}$ (Fig. 3(b)).

The GENRAY EBW ray tracing code requires rays to be launched inside the plasma as EBWs, following conversion from electromagnetic waves launched outside the plasma. The EBW launch parameters input to the GENRAY ray tracing calculations were determined as a result of an optimized EBW plasma-antenna coupling study conducted using the GLOSI 1-D wave equation solver [12]. This study was conducted for a launch frequency of $14 \mathrm{GHz}$, a frequency that mode converts to EBWs between the fundamental and second harmonic electron cyclotron resonance frequencies outside the last closed flux surface, as shown in Fig. 2. The launch polarization was adjusted to 
obtain the maximum EBW conversion efficiency as a function of the perpendicular and parallel wavenumber ( $n_{\perp}$ and $n_{/ /}$, respectively). Figure 4(a) shows a plot of contours of EBW coupling efficiency as a function of $n_{\perp}$ and $n_{/ /}$for $14 \mathrm{GHz}$ electromagnetic waves launched into the plasma with a similar edge magnetic field to the equilibrium of Fig. 1 and with a density scale length of $1 \mathrm{~cm}$ at the mode conversion layer. This density scale length is typical of an L-mode edge on NSTX. Efficient coupling of near-circular polarized electromagnetic waves was found for launched $n_{\perp} \sim 0$ and launched $n_{/ /} \sim \pm 0.55$. Similar calculations for an H-mode edge, shown in Fig.4 (b), show efficient EBW coupling over a wider range of $n_{\perp}$ and $n_{/ /}$, as a consequence of the steeper H-mode edge density gradient.

The GENRAY modeling used 48 EBW rays launched from inside the last closed flux surface, with either $-0.6<n_{/ /}<-0.5$ or $0.5<n_{/ /}<0.6$ and with the power distributed poloidally over a distance of $10 \mathrm{~cm}$. The poloidal angle of the center of the EBW launcher was adjusted between -80 and +80 degrees. Figure 5 shows the $n_{/ /}$variation for $14 \mathrm{GHz}$ EBW rays launched at 60 degrees below the midplane and with the EBW rays launched with $-0.6<n_{/ /}<-0.5$, plotted versus the poloidal distance from the EBW mode conversion layer. 99\% of the power is damped in the shaded region in the plot, where $n_{/ /}$ $=-0.4$ to -1.5 and $\omega / \omega_{c e}=1.5$ to 1.8 . Figure 6 (a) shows the profile of $14 \mathrm{GHz} \mathrm{EBW}$ power deposited to electrons versus normalized minor radius, calculated by CQL3D for $1 \mathrm{MW}$ of input EBW power. The EBW power is deposited between $\mathrm{r} / \mathrm{a}=0.6$ and $\mathrm{r} / \mathrm{a}=$ 0.75. Figure 6(b) shows the EBW-driven current density versus normalized minor radius 
calculated by CQL3D. The peak driven current density is $19 \mathrm{~A} / \mathrm{cm}^{2}$ at $\mathrm{r} / \mathrm{a}=0.7$ and the current drive efficiency is $44.7 \mathrm{kA} / \mathrm{MW}$.

Figure 7 shows the dependence of EBWCD efficiency on the poloidal angle of the antenna, for EBW waves launched with $n_{/ /}$between -0.6 and -0.5 (filled circles) and between 0.5 and 0.6 (open circles). The peak current density is also plotted. For all cases second harmonic cyclotron damping was dominant and the driven current remained well localized radially between $\mathrm{r} / \mathrm{a}=0.6$ and $\mathrm{r} / \mathrm{a}=0.75$. Positive current was driven for EBWs launched with positive $n_{/ /}$well above the midplane and negative current was driven for EBWs launched with negative $n_{/ /}$well below the midplane. The $n_{/ /}$shift for the EBW rays in the plasma increased as the antenna was moved further away from the midplane and, as a result, the current drive efficiency increased. However, near the midplane, current was driven in both directions, significantly reducing the net current drive efficiency. A similar behavior has been noted for ion Bernstein waves [13]. In one case plotted in Fig. 7, with launch 10 degrees above the midplane and negative $n_{/ /}$, a net positive current was generated.

Modeling for higher frequency launch at $21 \mathrm{GHz}$ and $28 \mathrm{GHz}$, respectively above the second and third cyclotron harmonic at the plasma edge, was also investigated for the same plasma equilibrium. Results at $21 \mathrm{GHz}$ were very similar to the $14 \mathrm{GHz}$ results. At $21 \mathrm{GHz}$, current was driven between $\mathrm{r} / \mathrm{a}=0.65$ and $\mathrm{r} / \mathrm{a}=0.75$, but with the current drive efficiency being somewhat higher at $21 \mathrm{GHz}$. At $28 \mathrm{GHz}$ the overlap between the third and fourth electron cyclotron harmonics (Fig. 2) complicated access to the plasma for 
antenna poloidal angles above 25 degrees or below -25 degrees. At poloidal angles greater than 25 degrees most of the power was damped on the third harmonic near the plasma edge. However, small changes $(\sim 10 \%)$ in the toroidal field allowed access to fourth harmonic damping deeper in the plasma. At a launch angle of 20 degrees above or below the midplane the calculated current drive efficiency at $28 \mathrm{GHz}$ was about $50 \mathrm{kA} / \mathrm{MW}$. Close to the maximum for the $14 \mathrm{GHz}$ cases shown in Fig. 7. The deposition location and current drive profile were relatively resilient to changes in the electron temperature profile. Changing the magnitude of the electron temperature profile by $30 \%$, while keeping the profile shape the same, changed $n_{/ /}$at the EBW damping location by about $10 \%$ and the deposition location by only $2 \mathrm{~mm}$.

\section{DISCUSSION}

If we now calculate the dimensionless current drive efficiency, $\zeta_{e c}[14]$, defined as

$$
\zeta_{e c}=\frac{3.27 I_{p}(A) R(m) n_{e}\left(10^{19} m^{-3}\right)}{T_{e}(k e V) P(W)}
$$

where $I_{p}$ is the plasma current, $R$ is the major radius, $n_{e}$ is the electron density, $T_{e}$ is the electron temperature and $P$ is the input EBW power, for the case shown in Fig. 6, we find that $\zeta_{e c}=0.6$ at $\mathrm{r} / \mathrm{a}=0.7$. When NSTX equilibria with $\beta=20 \%$ and $\beta=30 \%$ were modeled, values of $\zeta_{e c}$ in the range 0.6 to 0.75 were obtained for EBWCD localized at r/a 0.7. This is about twice the value of $\zeta_{e c}$ calculated and measured for ECCD near the axis of a low aspect ratio Tokamak such as DIII-D [15]. Also, this EBWCD is driven well off axis in a region dominated by electron trapping. In contrast, in DIII-D at low $\beta, \zeta_{e c}$ 
decreases rapidly with r/a due to electron trapping, falling to 0.1 at $\mathrm{r} / \mathrm{a}=0.4$. Even at relatively high $\beta, \zeta_{e c}$ is only 0.2 at $\mathrm{r} / \mathrm{a}=0.4$. In contrast, Ohkawa EBWCD efficiency increases with r/a.

Recently, EBWCD experiments on Wendelstein 7-AS Stellarator have achieved $\zeta_{e c}=$ $0.43 \pm 0.1$ near the axis [16], 2-3 times the $\zeta_{e c}$ obtained using ECCD on Wendelstein 7-AS. However, in this case Fokker-Planck modeling shows that the EBWCD was via the conventional Fisch-Boozer [6] current drive mechanism and was more efficient than ECCD on the same machine because the wave interaction was with more energetic electrons that were well away from the trapped electron population.

In order to explain the high $\zeta_{e c}$ values predicted for off-axis EBWCD in the modeling of NSTX plasmas, in Figure 8 we plot contours indicating the strength of the quasi-linear diffusion operator versus the normalized perpendicular and parallel velocity calculated by CQL3D. This plot is for the case shown in Fig. 6, at r/a $=0.7$, the peak of the EBW power deposition profile. The diffusion operator is a maximum near the trapped-passing boundary and, consequently, particularly well suited to efficiently drive electrons from the passing negative $v_{/ /}$population to the trapped population. As a result, there are more electrons traveling in the positive $v_{/ /}$direction than there are in the negative $v_{/ /}$direction and so net electron current is driven. This current drive mechanism was originally predicted by Ohkawa [7] and has been proposed as an attractive mechanism for off-axis ECCD [16]. It is in the opposite direction to Fisch-Boozer [6] current drive, the mechanism normally employed for ECCD and, because the Ohkawa EBWCD mechanism 
requires a trapped electron population it becomes more efficient the further off-axis it is driven. For a high pressure ST plasma this feature is critical because ST's have very large trapped particle populations on the low field side of the magnetic axis and need externally driven off axis current between $\mathrm{r} / \mathrm{a} \sim 0.4$ and $\mathrm{r} / \mathrm{a} \sim 0.8$ to remain stable.

Presently, we are considering a high power EBWCD system for NSTX and, based on the EBWCD estimates obtained so far from the GENRAY/CQL3D modeling, we conclude that about $3 \mathrm{MW}$ of EBW power will be needed to sustain the required $\sim 100 \mathrm{kA}$ of offaxis current. Practical limitations resulting from the higher electromagnetic wave diffraction at $14 \mathrm{GHz}$ and the lack of an existing commercial high power rf source with relatively long (2-5 s) pulse lengths at 14 or $21 \mathrm{GHz}$, make $28 \mathrm{GHz}$ the preferred operating frequency for the NSTX EBWCD system. It should be noted that, unlike ECCD, $n_{\perp}$ and $n_{/ /}$at the launcher must match the conditions required for efficient mode conversion to EBWs, so the location of the driven current needs to be adjusted by varying the toroidal magnetic field, rather than by steering the antenna launching mirror as is done with ECCD.

\section{ACKNOWLEDGEMENTS}

The authors would like to thank Prof. A. Bers, Dr. A. Ram and J. Decker of MIT for providing information regarding their work on Ohkawa ECCD. This work was supported by US Department of Energy contract numbers DE-AC02-76CH03073 and DE-FG03-02ER54684. 


\section{REFERENCES}

[1] M.C. Zarnstorff, et al., Phys. Rev. Lett. 60, 1306 (1988)

[2] M. Ono, S. Kaye, M. Peng, et al., Proceedings $17^{\text {th }}$ IAEA Fus. Energy Conf. (International Atomic Energy Agency, Vienna, Austria, 1999), Vol. 3, p. 1135

[3] C. E. Kessel, E.J. Synakowski, and the NSTX Research Team. "Advanced ST Plasma Scenario Simulations for NSTX", Proceedings $20^{\text {th }}$ International Conference on Fusion Energy, Vilamoura, Portugal (International Atomic Energy Agency, Vienna, 2004)

[4] J. Hosea, V. Arunasalam, and R. Cano, Phys. Rev. Lett. 39, 408 (1977)

[5] C.B. Forest, P.K. Chattopadhyay, R.W. Harvey, and A.P. Smirnov, Phys. Plasmas, 7, $1352(2000)$

[6] N.J. Fisch and A. Boozer, Phys. Rev. Lett. 45, 720 (1980)

[7] T. Ohkawa, General Atomics Report no. 4356.007 .001 (1976)

[8] A.P. Smirnov and R.W. Harvey, Bull. Am. Phys. Soc. 40, 1837 (1995)

[9] R.W. Harvey and M.G. McCoy, Proceedings of the IAEA Technical Committee on Advances in Simulation and Modeling of Thermonuclear Plasmas, Montreal, Quebec (International Atomic Energy Agency, Vienna, 1993), p. 489; USDOC NTIS Doc. No. DE93002962

[10] S. Jardin, N. Pomphrey, and J. Delucia, J. Comput. Phys, 66, 481 (1986)

[11] R.J. Hawryluk in Physics of Plasmas Close to Thermonuclear Conditions 119 (CEC, Brussels, 1980)

[12] C.Y. Wang, D.B. Batchelor, M.D. Carter, E.F. Jaeger, and D.C. Stallings, Phys. Plasmas 2, 2760 (1995) 
[13] M. Ono, Phys. Fluids B, 5, 241 (1993)

[14] T.C. Luce, Y. R. Lin-Liu, R. W. Harvey, et al., Phys. Rev. Lett., 83, 4550 (1999)

[15] C.C. Petty, R. Prater, J. Lohr, et al., Nucl. Fusion, 42, 1366 (2002)

[16] H.P. Laqua, H. Maassberg, N.B. Marushchenko. F. Volpe, A. Weller, and W7-AS Team, Phys. Rev. Lett., 90, 075003-1 (2003)

[17] J. Decker "ECCD for Advanced Tokamak Operations Fisch-Boozer versus Ohkawa Methods", Proceedings $15^{\text {th }}$ Topical Conference on Radio Frequency Power in Plasmas, edited by C.B. Forest, (AIP Conf. Proc. 694, Melville, New York, 2003), p. 447 


\section{FIGURE CAPTIONS}

\section{Figure 1}

Poloidal cross section of an NSTX $\beta=42 \%$ equilibrium showing the location of the EBW antenna used for the GENRAY modeling. The 48 EBW rays from the GENRAY modeling are also shown.

\section{Figure 2}

Characteristic frequencies versus major radius for an NSTX $\beta=42 \%$ equilibrium. The fundamental and lowest six harmonics of the electron cyclotron resonance (thin solid lines) show the existence of a magnetic well on the outboard side of the axis. Also, plotted are the right and left hand cutoff, the upper hybrid resonance and the electron plasma frequency.

\section{Figure 3}

(a) Electron temperature and (b) electron density profiles versus normalized minor radius used to model the NSTX $\beta=42 \%$ equilibrium.

\section{Figure 4}

Maximum coupling to EBW waves versus poloidal and toroidal angle for $14 \mathrm{GHz}$ electromagnetic waves. The magnetic field at the EBW coupling layer is similar to that at the edge of the equilibrium shown in Fig. 1. The coupling efficiency is calculated for an electron density scale length at the mode conversion layer of (a) $1 \mathrm{~cm}$ and (b) $0.25 \mathrm{~cm}$, corresponding to density scalelengths at the edge of L-mode and H-mode NSTX plasma, respectively. 


\section{Figure 5}

Parallel wavenumber versus poloidal distance for 48 EBW rays with a frequency of 14 $\mathrm{GHz}$ calculated with GENRAY for launch 60 degrees below the midplane of the equilibrium shown in Fig. 1. The shaded region shows where $99 \%$ of the EBW power is deposited.

\section{Figure 6}

(a) EBW power deposition and (b) EBW-driven current density versus r/a, calculated by CQL3D for $1 \mathrm{MW}$ of $14 \mathrm{GHz}$ power launched 60 degrees below midplane into the $\beta=$ $42 \%$ NSTX plasma equilibrium.

\section{Figure 7}

EBW current drive efficiency versus poloidal angle of the EBW launcher for a launch frequency of $14 \mathrm{GHz}$, filled circles are for EBW rays launched with $-0.6<n_{/ /}<-0.5$ and open circles are for EBW rays launched with $0.5<n_{/ /}<0.6$.

\section{Figure 8}

Contours indicating the strength of the quasi-linear diffusion operator versus the normalized perpendicular and parallel velocity at the peak of the EBW power deposition profile located at $\mathrm{r} / \mathrm{a}=0.7$ for $1 \mathrm{MW}$ of $14 \mathrm{GHz}$ power launched at 60 degrees below the midplane into the $\beta=42 \%$ NSTX plasma equilibrium in Fig. 1. The quasi-linear diffusion peaks near the trapped-passing boundary. 


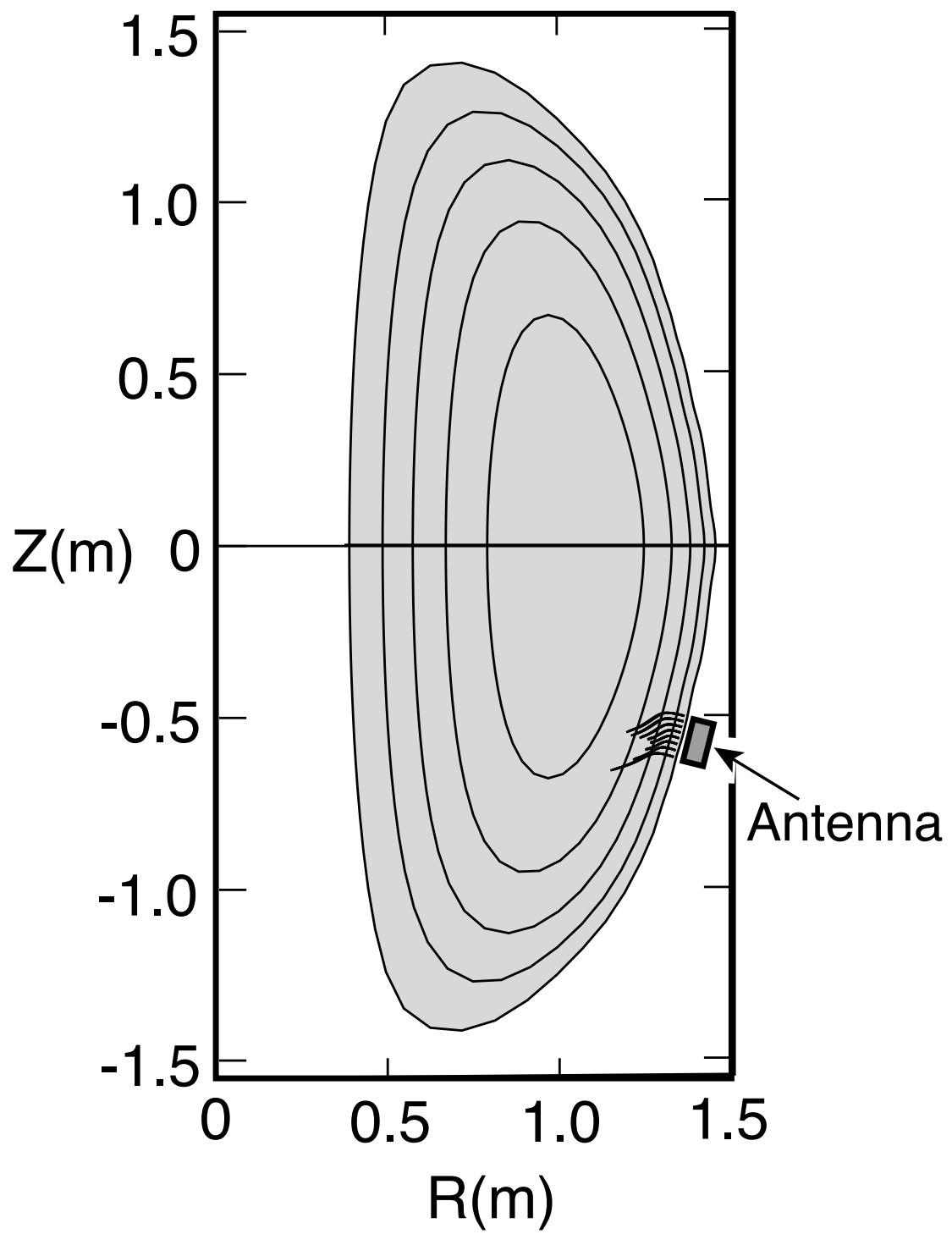

Taylor_Figure 1 


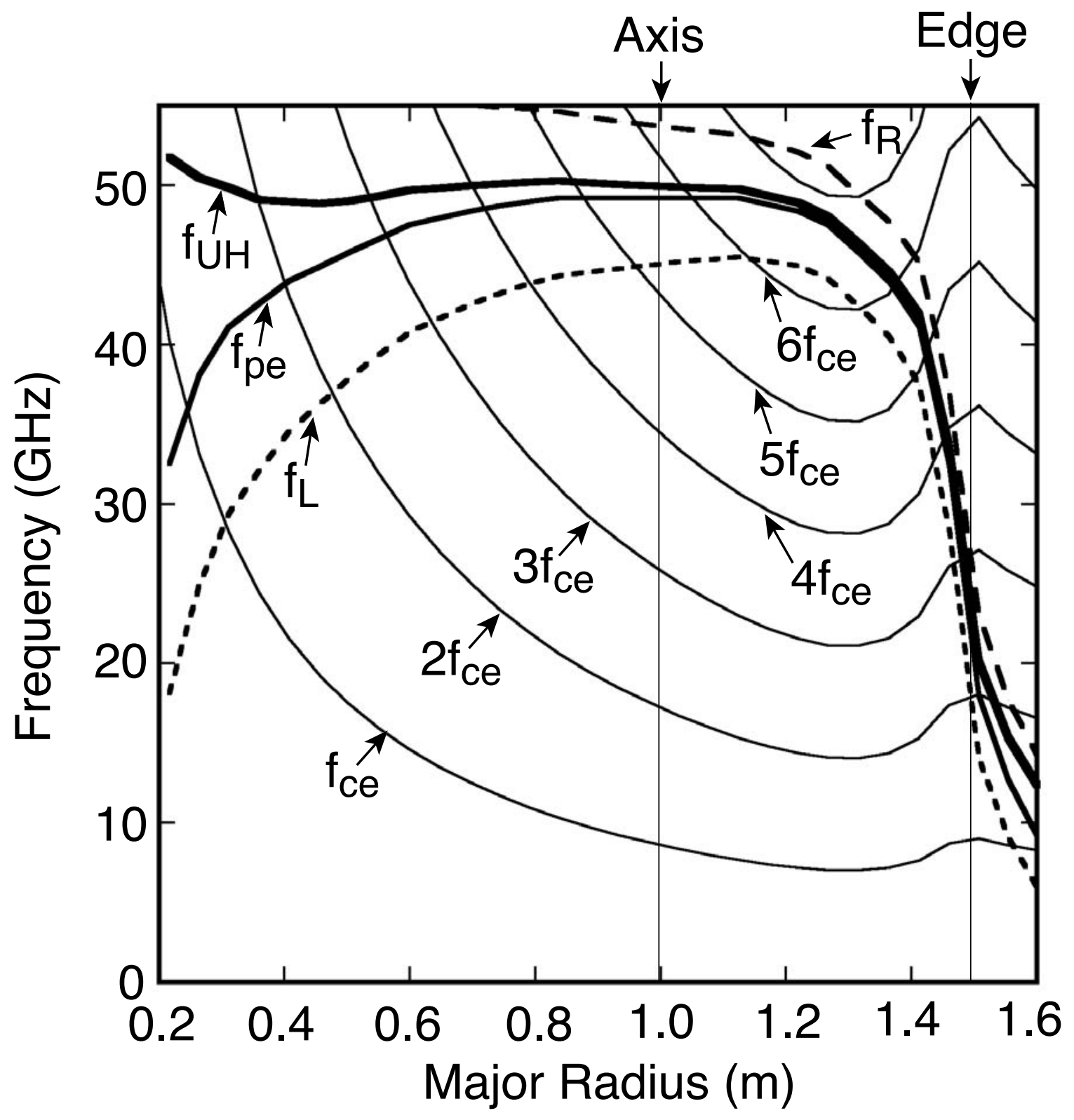

Taylor_Figure 2 

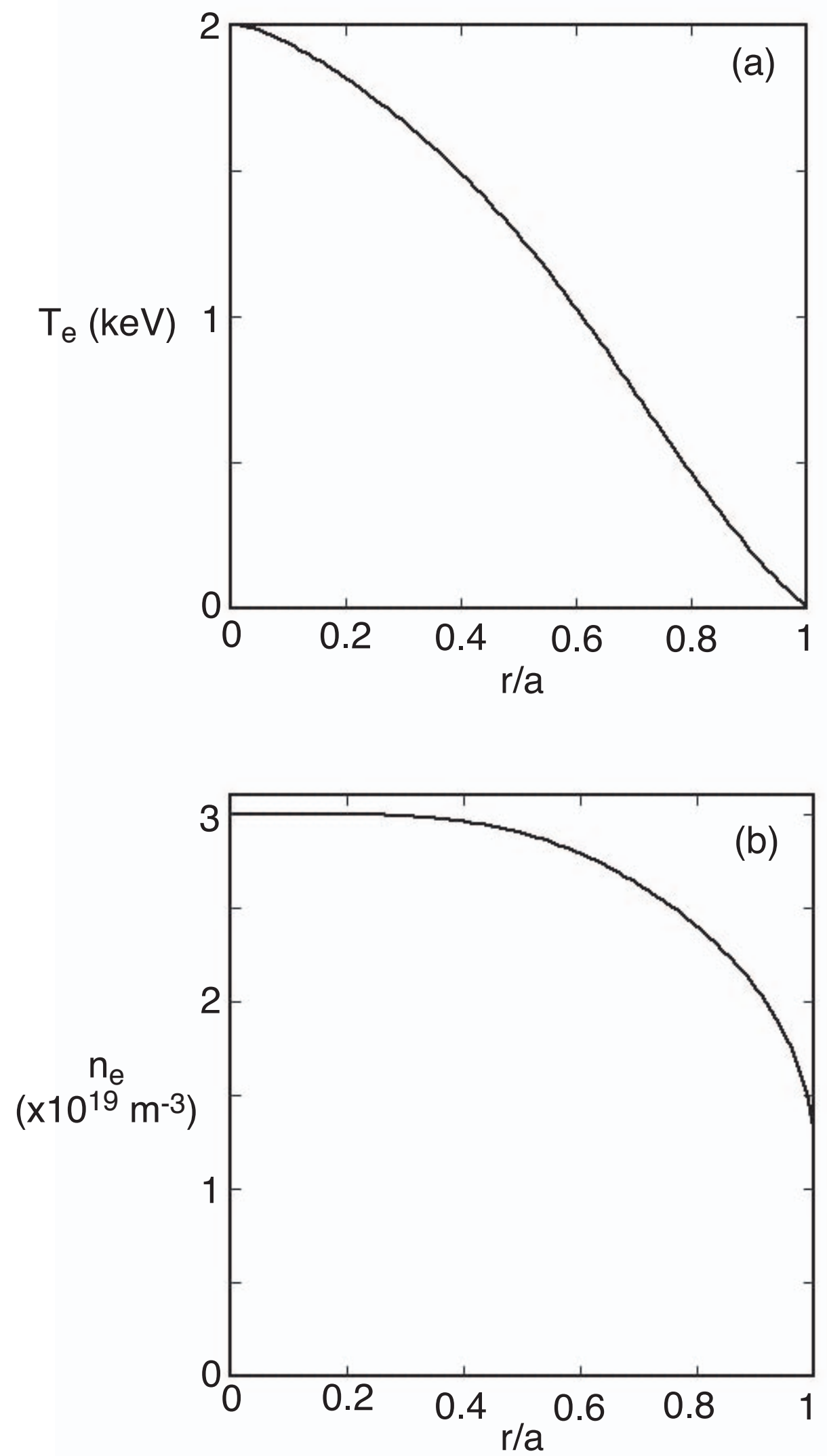

Taylor_Figure 3 
(a)

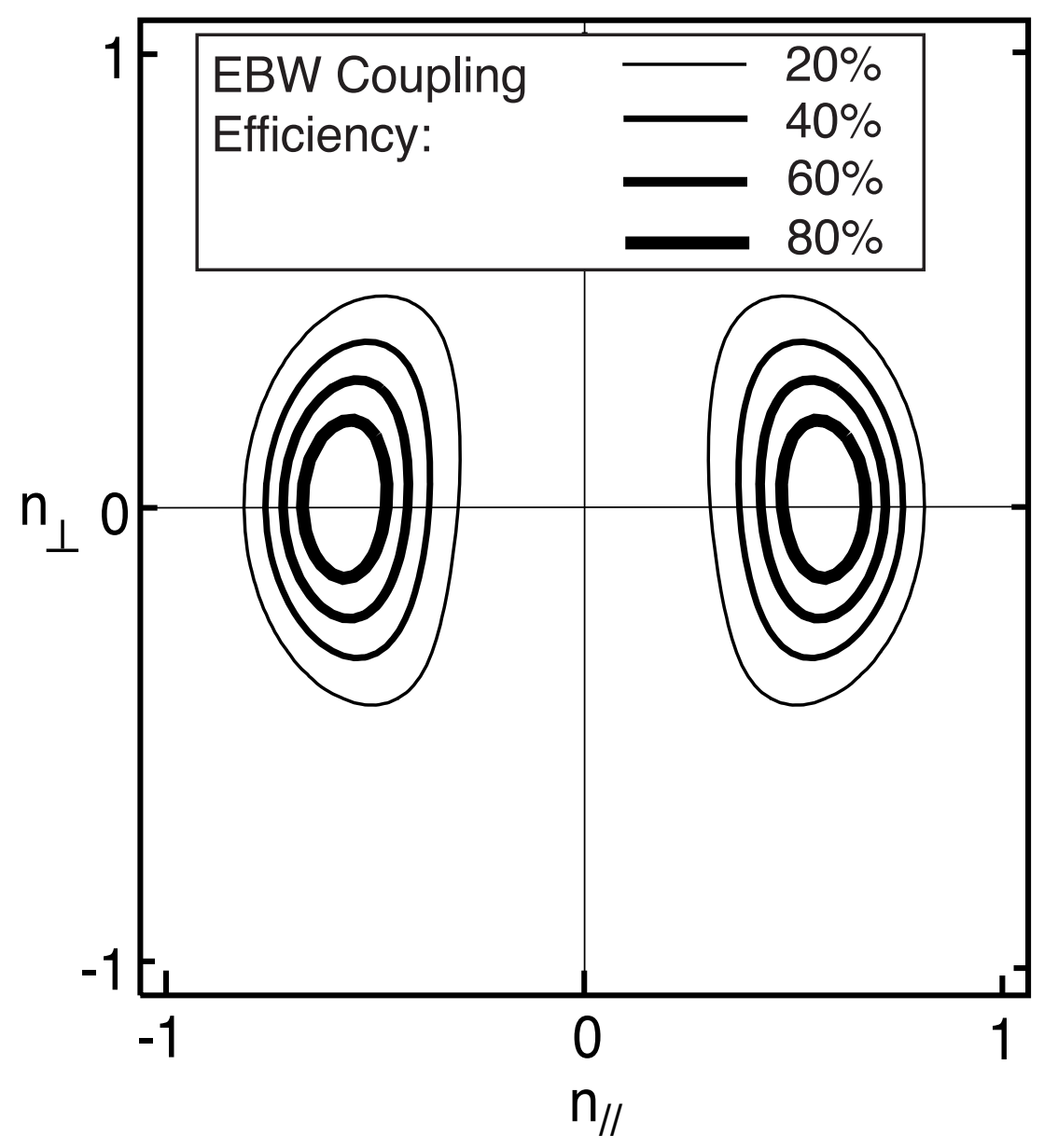

(b)

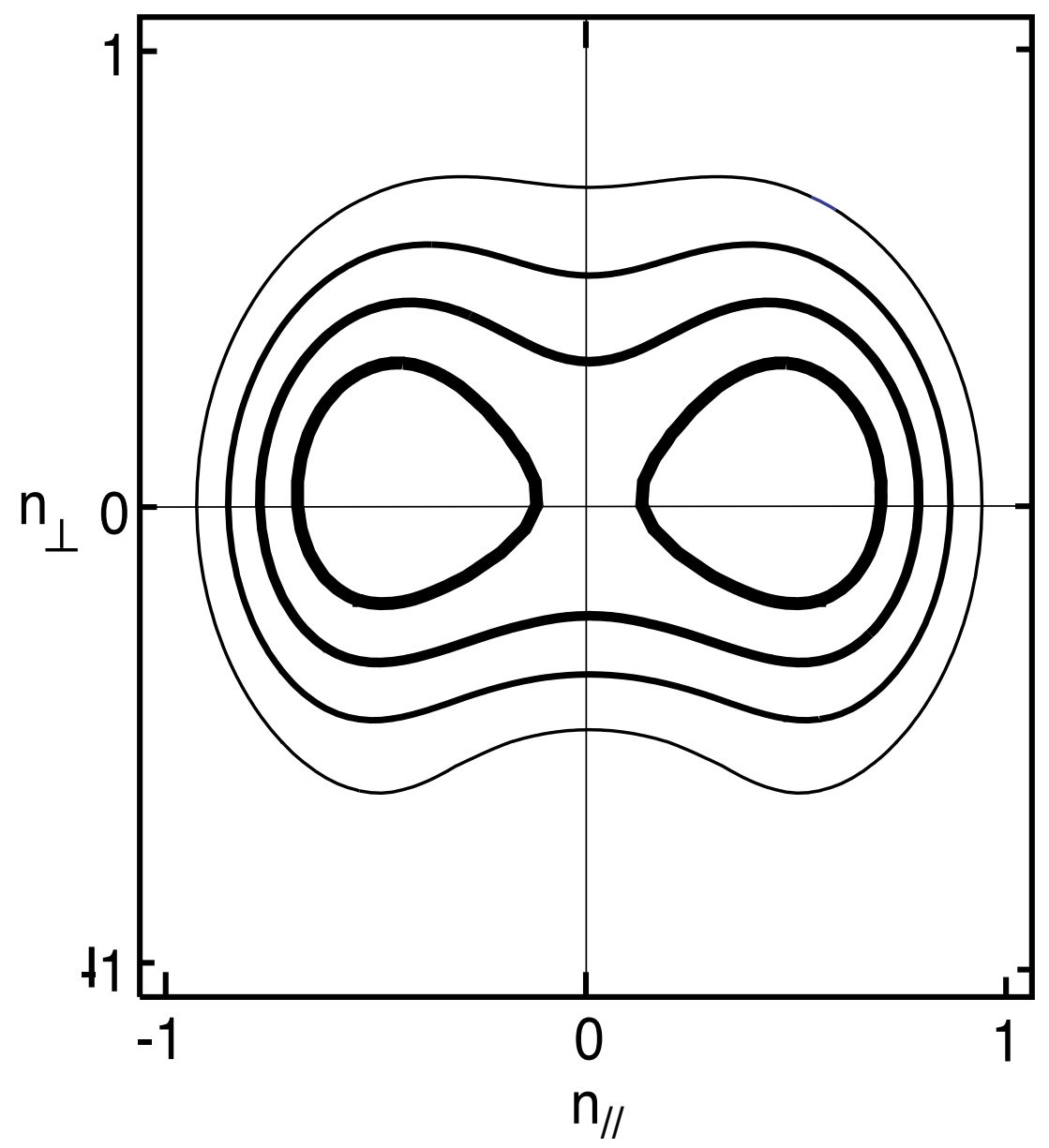

Taylor_Figure 4 


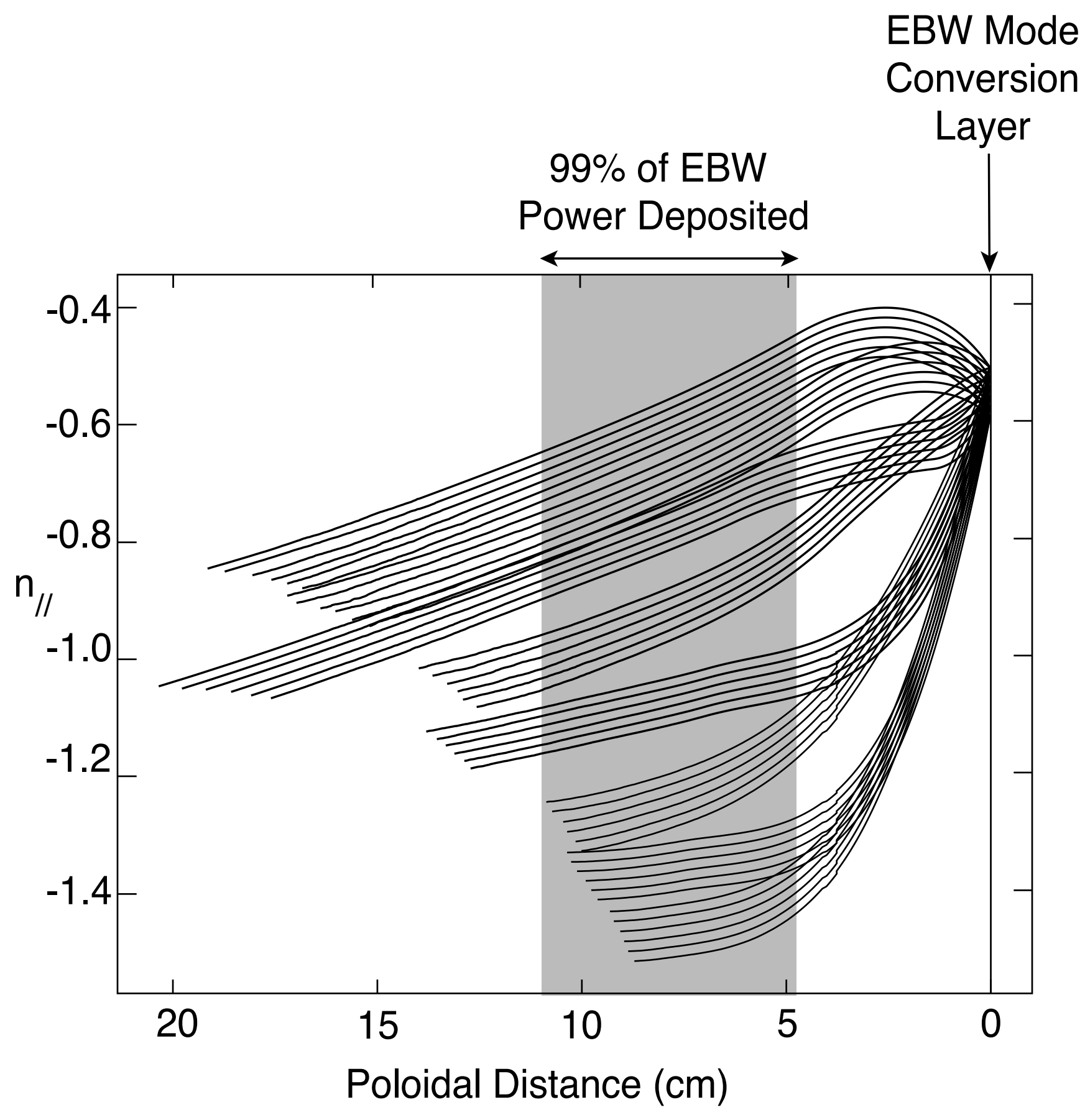

Taylor_Figure 5 
(a)

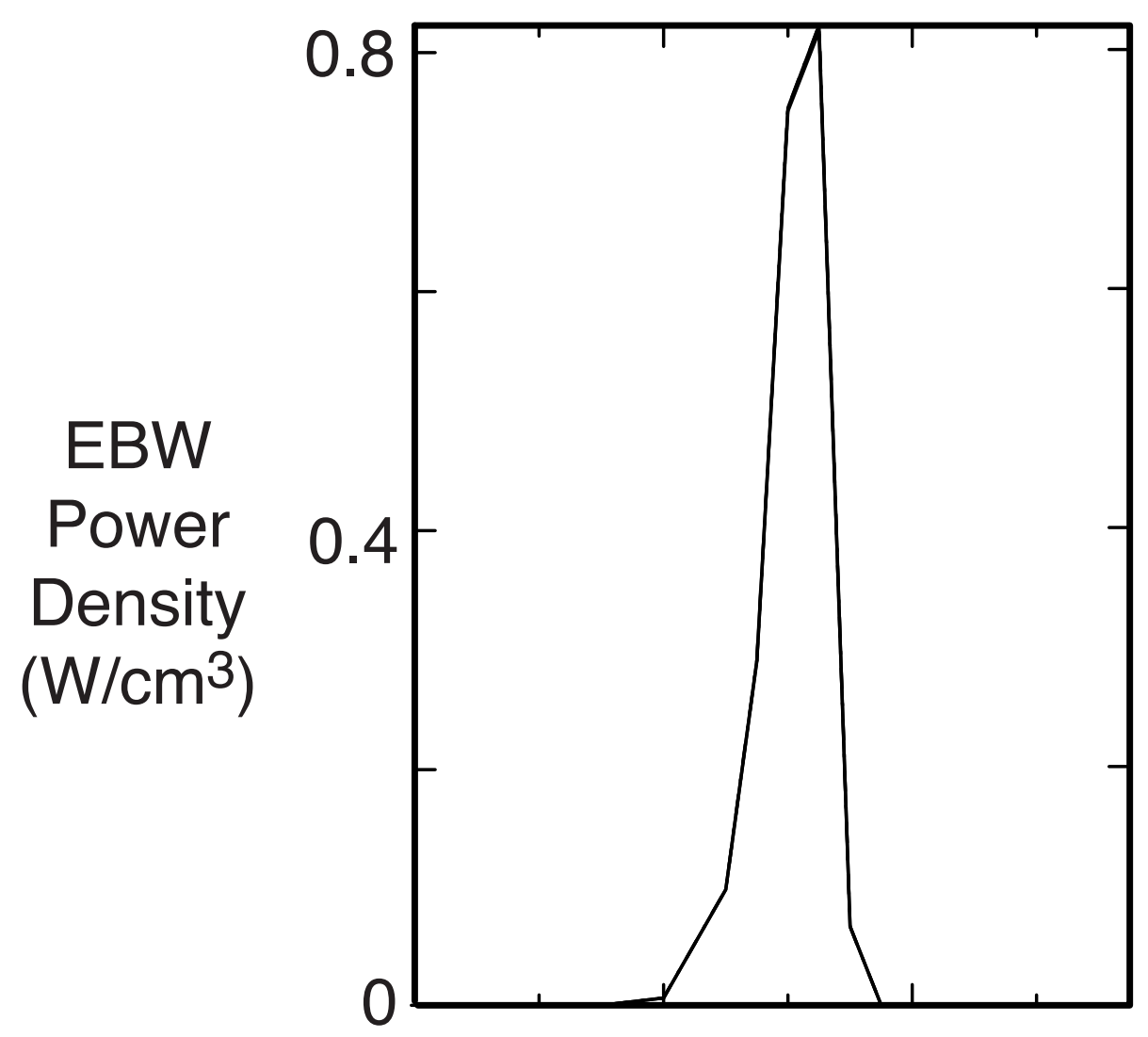

(b)

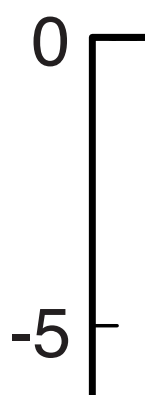

EBW-Driven

Current

Density -10 -

$\left(\mathrm{A} / \mathrm{cm}^{2}\right)$

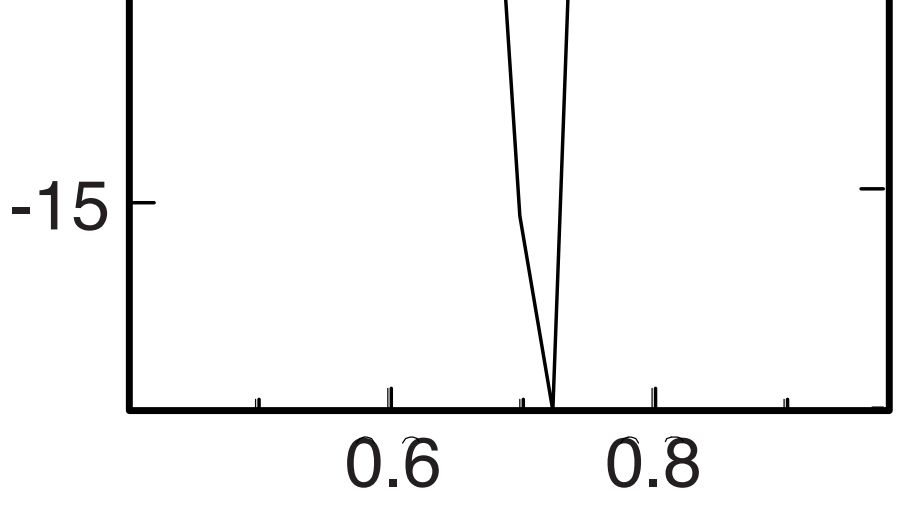

r/a

Taylor_Figure 6 


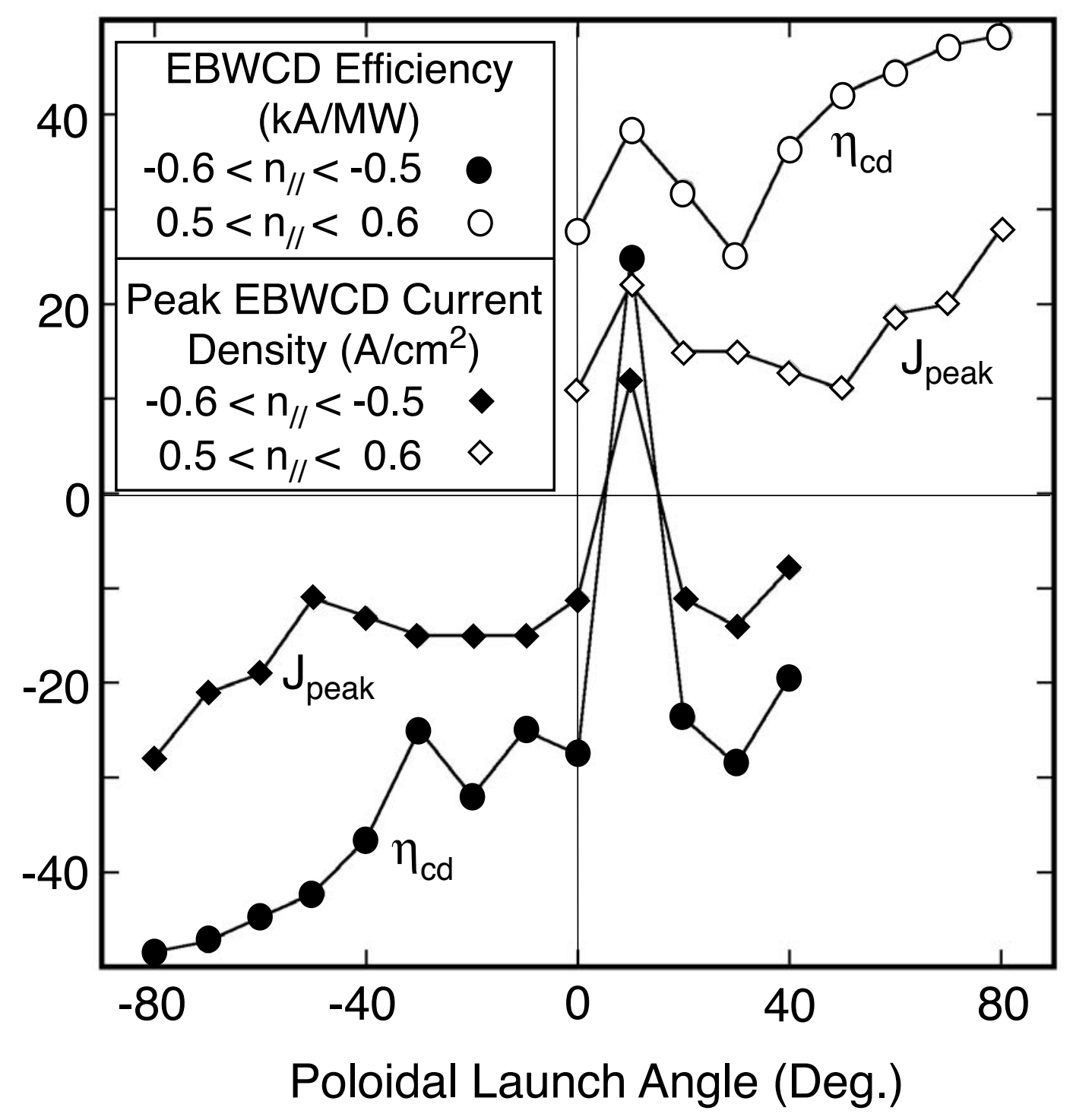

Taylor_Figure 7 


\begin{tabular}{|l|}
\hline$r / a=0.7$ \\
$v_{0} @ 30 \mathrm{keV}$
\end{tabular}

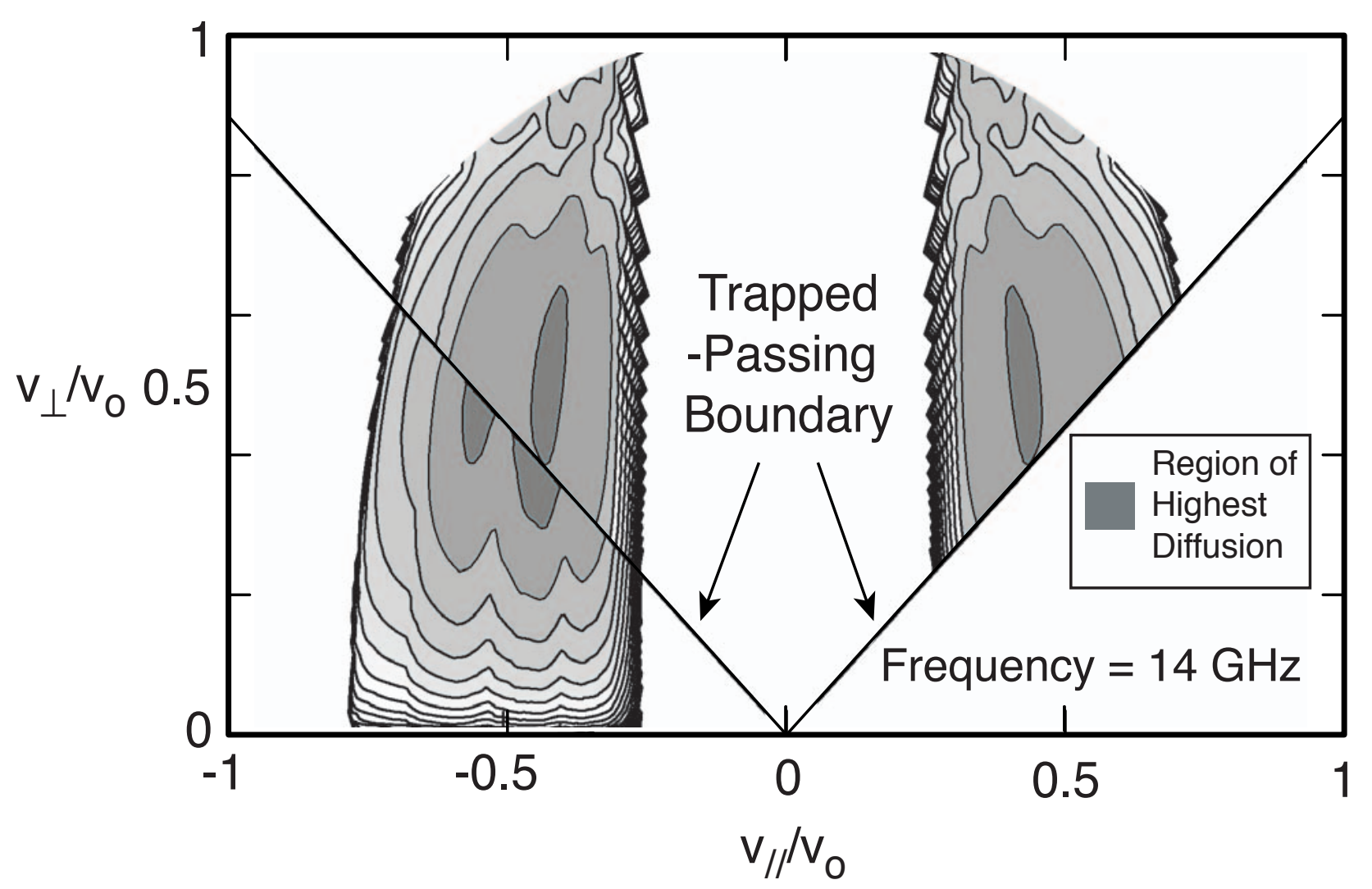

Taylor_Figure 8 


\section{External Distribution}

Plasma Research Laboratory, Australian National University, Australia

Professor I.R. Jones, Flinders University, Australia

Professor João Canalle, Instituto de Fisica DEQ/IF - UERJ, Brazil

Mr. Gerson O. Ludwig, Instituto Nacional de Pesquisas, Brazil

Dr. P.H. Sakanaka, Instituto Fisica, Brazil

The Librarian, Culham Laboratory, England

Mrs. S.A. Hutchinson, JET Library, England

Professor M.N. Bussac, Ecole Polytechnique, France

Librarian, Max-Planck-Institut für Plasmaphysik, Germany

Jolan Moldvai, Reports Library, Hungarian Academy of Sciences, Central Research Institute for Physics, Hungary

Dr. P. Kaw, Institute for Plasma Research, India

Ms. P.J. Pathak, Librarian, Institute for Plasma Research, India

Ms. Clelia De Palo, Associazione EURATOM-ENEA, Italy

Dr. G. Grosso, Instituto di Fisica del Plasma, Italy

Librarian, Naka Fusion Research Establishment, JAERI, Japan

Library, Laboratory for Complex Energy Processes, Institute for Advanced Study, Kyoto University, Japan

Research Information Center, National Institute for Fusion Science, Japan

Dr. O. Mitarai, Kyushu Tokai University, Japan

Dr. Jiangang Li, Institute of Plasma Physics, Chinese Academy of Sciences, People's Republic of China

Professor Yuping Huo, School of Physical Science and Technology, People's Republic of China

Library, Academia Sinica, Institute of Plasma Physics, People's Republic of China

Librarian, Institute of Physics, Chinese Academy of Sciences, People's Republic of China

Dr. S. Mirnov, TRINITI, Troitsk, Russian Federation, Russia

Dr. V.S. Strelkov, Kurchatov Institute, Russian Federation, Russia

Professor Peter Lukac, Katedra Fyziky Plazmy MFF UK, Mlynska dolina F-2, Komenskeho Univerzita, SK-842 15 Bratislava, Slovakia

Dr. G.S. Lee, Korea Basic Science Institute, South Korea

Institute for Plasma Research, University of Maryland, USA

Librarian, Fusion Energy Division, Oak Ridge National Laboratory, USA

Librarian, Institute of Fusion Studies, University of Texas, USA

Librarian, Magnetic Fusion Program, Lawrence Livermore National Laboratory, USA

Library, General Atomics, USA

Plasma Physics Group, Fusion Energy Research Program, University of California at San Diego, USA

Plasma Physics Library, Columbia University, USA

Alkesh Punjabi, Center for Fusion Research and Training, Hampton University, USA

Dr. W.M. Stacey, Fusion Research Center, Georgia Institute of Technology, USA

Dr. John Willis, U.S. Department of Energy, Office of Fusion Energy Sciences, USA

Mr. Paul H. Wright, Indianapolis, Indiana, USA 
The Princeton Plasma Physics Laboratory is operated by Princeton University under contract with the U.S. Department of Energy.

\author{
Information Services \\ Princeton Plasma Physics Laboratory \\ P.O. Box 451 \\ Princeton, NJ 08543
}

Phone: 609-243-2750

Fax: 609-243-2751

e-mail: pppl_info@pppl.gov

Internet Address: http://www.pppl.gov 